\title{
Mullerian Agenesis in One of the Non-Identical Twins: A Case Report and Literature Review
}

\author{
Shweta Thapa K. C. , Cunjian Yi \\ Department of Gynecology and Obstetrics, 1st Clinical Medical School of Yangtze University, Jingzhou, China \\ Email: *msshwetath@hotmail.com
}

How to cite this paper: Thapa K. C., S. and Yi, C.J. (2018) Mullerian Agenesis in One of the Non-Identical Twins: A Case Report and Literature Review. Yangtze Medicine, 2, 82-88.

https://doi.org/10.4236/ym.2018.22009

Received: February 9, 2018

Accepted: June 8, 2018

Published: June 11, 2018

Copyright $\odot 2018$ by authors and Scientific Research Publishing Inc. This work is licensed under the Creative Commons Attribution International License (CC BY 4.0).

http://creativecommons.org/licenses/by/4.0/

\begin{abstract}
Mullerin agenesis also referred as mullerian aplasia, Mayer-RokitanskyKuster-Hauser Syndrome (MRKH) or vaginal agenesis is the congenital anomaly of vertical fusion defect of mullerian system resulting in variable abnormalities of female reproductive tract with normal functioning ovaries. It is second most common cause of primary amenorrhea after gonadal agenesis. The occurrence of mullerian agenesis in twins is very rare. We present the case of one of the non-identical twins, 22 years female, with primary amenorrhea. Her elder twin sister had a normal female reproductive system. In our case, diagnosis was supported by presence of definitive primary amenorrhea with well-developed secondary sexual characteristics. Normal physiological hormonal levels ruled out the ovarian or pituitary pathology. Imaging studies like ultrasonography and magnetic resonance imaging (MRI) provided additional confirmation.
\end{abstract}

\section{Keywords}

Mullerian Agenesis, Primary Amenorrhea, Twins

\section{Introduction}

Primary amenorrhea is often the first presenting symptom in mullerian agenesis. A thorough history and physical examination focusing on pubertal development is essential [1]. Mayer-Rokitansky-Kuster-Hauser (MRKH) syndrome is a mullerian dysgenesis syndrome that involves complete agenesis of the vagina, without uterine structures, normal ovarian function, normal secondary sexual characteristics [2]. MRKH is the second most common cause of primary amenorrhea with a reported incidence of 1:4000 to 1:5000 live female births [1] [2].

The occurrence of mullerian agenesis in twins is very rare. We present at case, 22 years female, one of the non-identical twins, with primary amenorrhea due to 
mullerian agenesis. Her twin sister had a normal female reproductive system.

\section{Case Report}

A 22 years old Medical student was under evaluation in our hospital Gynaecology Department for primary amenorrhoea. After history, physical examination, laboratory and imaging investigations, her diagnosis was mullerian agenesis (MRKH syndrome) with complete absence of uterus and upper vagina and cervix. The diagnosis of MRKH syndrome was confirmed by imaging studies.

While in the history, the patient reported having a non-identical twin sister. She was the youngest among the twins of consanguineous marriage in a monogamous family. Her twin sister had menarche at the age 14 years with normal development of secondary sexual characteristics and normal genitourinary functions. The first twin had no any physical or systemic abnormalities. Both twins delivered at home, at the interval of $30 \mathrm{~min}$ through normal vaginal delivery after 35 weeks of gestation. There was no abnormalities detected at birth in both twins. There was no any significant perinatal and postnatal events as well as no antenatal check-ups done. No history of primary amenorrhea or infertility in the family. The twins are from Muslim ethnicity of South East Asia.

Our patient (second twin) had normal developmental milestones. Her secondary sexual characteristics, external genitalia are normal. There was no history of hearing impairment, no syndactyly, cardiac or renal abnormalities. No history of pelvic surgery or use of contraceptive pills, other medications. No history of abnormal facial hair growth, change in voice, nipple discharge, heat or cold intolerance, no history of weight loss or gain. Her systemic examinations are within normal limits.

On laboratory investigation, hormone profile are within normal limits. Follicular Stimulating Hormone (FSH) $-2.16 \mathrm{mIU} / \mathrm{mL}$ (normal range $0-4.5$ $\mathrm{mIU} / \mathrm{mL}$ ), Luteinizing Hormone $(\mathrm{LH})-1.78 \mathrm{mIU} / \mathrm{mL}$ (normal range 1.9 - 12.5 $\mathrm{mIU} / \mathrm{mL}$ ), Prolactin (PRL)-563.90 $\mu \mathrm{IU} / \mathrm{L}$ (normal-106 to $850 \mu \mathrm{IU} / \mathrm{L}$ ), Progesterone (P)-2.35 ng/mL (normal range- 2 to $25 \mathrm{ng} / \mathrm{mL}$ ), Testosterone-27.68 ng/dl (normal range 50 - $120 \mathrm{ng} / \mathrm{dl}$ ), Estradiol (E2)-88.49 pg/mL (normal range 30 $400 \mathrm{pg} / \mathrm{mL}$ ).

On further investigation, ultrasound scan revealed normal ovaries and abdominal organs. However, uterus and cervix with upper vagina not visualized (Figure 1). This finding was further confirm by MRI scan (Figure 2 \& Figure $3)$.

\section{Discussion}

Mullerian agenesis develops due to the embryological growth failure of the mullerianducts, which result in the complete aplasia or hypoplasia of uterus, fallopian tube and vagina. It is also preferable with entities as Mullerian Aplasia, Mayer Rokitasky Kuster Haruse Syndreome, MURCS-Mullerian duct aplasia, Renal dysplasia and Cervical Somite anomalies, CAUV: Congenital Absence of 


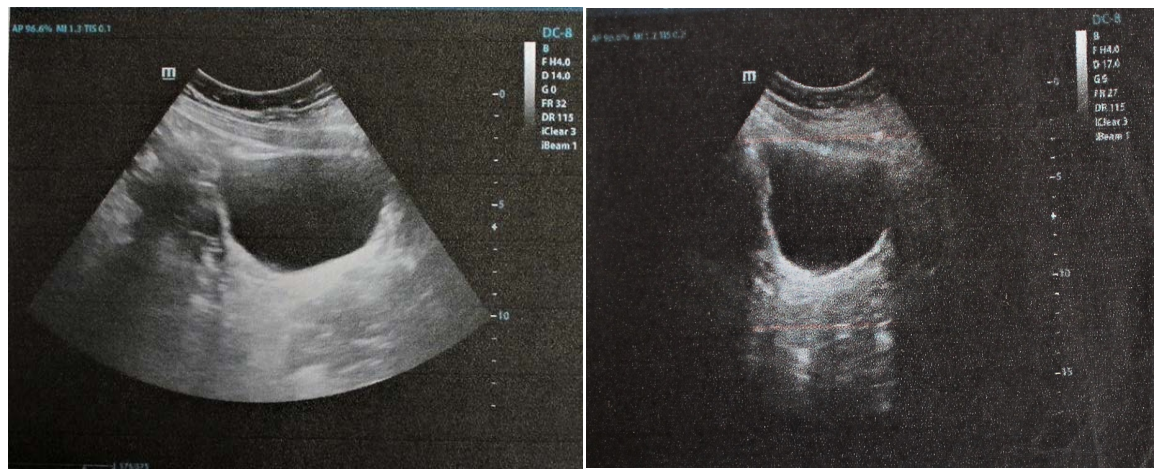

Figure 1. Imaging study. Ultrasound: showing normal abdominal and pelvic organs except non visualization of uterus, cervix and upper vagina.

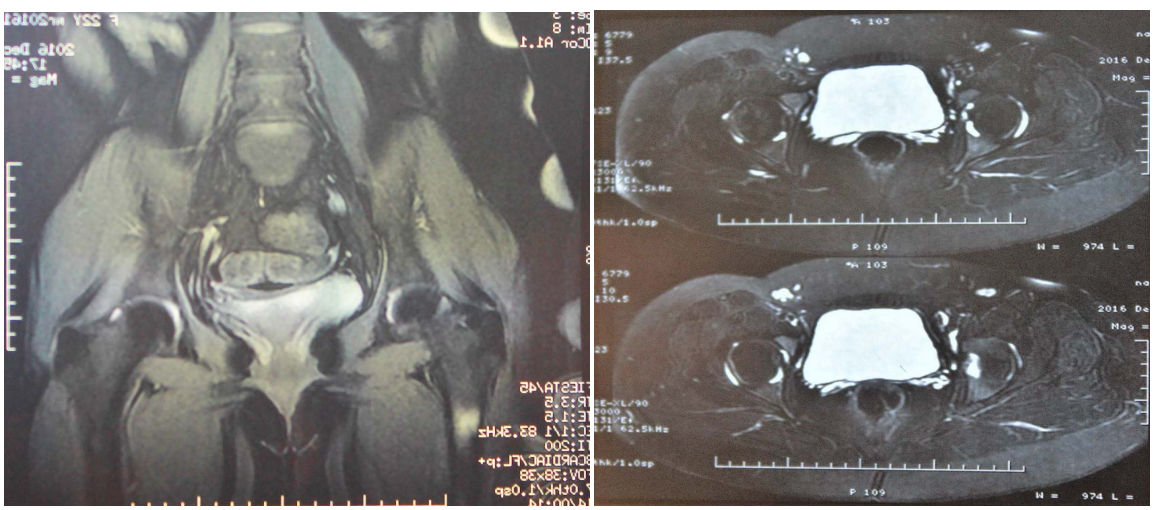

Figure 2. Imaging study. MRI scan T2 weighted images showing absence of uterus in coronal and axial sections.

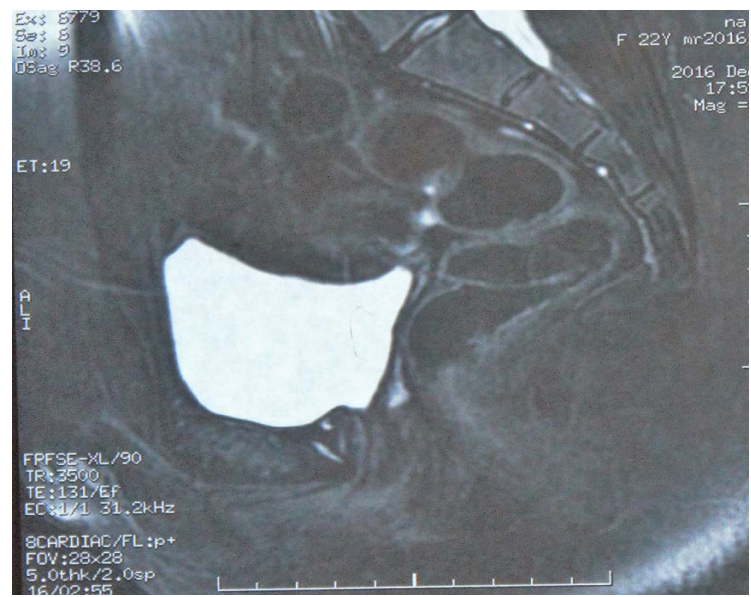

Figure 3. Imaging study. MRI scan T2 weighted image showing absence of uterus in sagittal section.

Uterus and Vagina. GRES: Genital Renal Ear Syndrome. MRKH syndrome divided into two types: Type I MRKH syndrome-characterized by an isolated absence of the uterus, fallopian tube and proximal two thirds of the vagina or type II MRKH syndrome-associated with renal, cardiac and skeletal anomalies, short stature, and auditory defects [3]. 
MRKH syndrome remain undetected until puberty, women present with primary amenorrhea with underlying well developed secondary sexual characteristics and normal external genitalia with functional ovaries and karyotype 46, XX without visible chromosomal anomaly [4]. Incidence is about 1 in 4000 to 5000 female births [1] [2] [5].

According to our best knowledge, Reports of MRKH in non-identical twins are rare in the literature. We searched the relative English-language publications in PubMed database from 1998 to June 2017. We found 9 publications that reported the MRKH suffered in siblings or twins [1] [2] [6]-[12]. Most of these twin cases (9/10) are Monozygotic Twins [2] [6] [7] [8] [9], but only one is non-identical twins [1]. A Study has reported the siblings with mullerian agenesis [10]; Additional studies have shown a discordance of the mullerian agenesis syndrome in family cases [11] [12].

Judith G Hall [13], twins have intrigued civilisations across the centuries. Twins are not rare: the spontaneous rate of twinning is about 1 in 80 live births, which means that about 1 in 40 babies born would be a twin. The rate of monozygotic twinning has been constant around the world, with variability being attributable to the rate of dizygotic twinning, so that the ratio of monozygotic to dizygotic twinning varies strikingly. The prevalence of spontaneous twinning in live births ranges from about 6 in 1000 in Asia. Twinning depends on the notion that monozygotic twins come from one fertilised egg (zygote), and thus their genetic makeup would be expected to be identical, hence the lay use of the term identical twins when referring to monozygotic twins. Thus, differences between twins of a monozygotic pair (discordance) would be expected to be attributable to environmental factors-since their genetic inheritance for practical reasons is the same-whereas Dizygotic Twins (with two separately fertilised eggs) would be expected to be different on the basis of both genetic and environmental factors [13].

In 2007 Dec, Geyoushi B. [1] (Queen Mary's Hospital UK), reported a case of non-identical 18-year-old twins presented with primary amenorrhea. They both had well developed secondary sexual characteristics, with no menarche. One of the twins complained of lower abdominal pain. In one twin there was present of right and left ovary with no cervix and uterine streak and second twin have polycystic ovaries with absent of fallopian tube, cervix and uterus. Both were of normal karyotypes 46XX. The MRI scan of both twins showed normal kidney on both sides with no evidence of skeletal anomalies. The hormonal profile of both twins were within normal limits. In this case both twins have uterine anomalies but in our case 1st twin is normal. And this case is from Europe and age of presentation is also earlier than our case.

In 2009, Ugonna A. Duru and Marc R. Laufer [2] (Children's Hospital Boston, Harvard Medical School, Boston, Massachusetts, USA), reported mullerian agenesis in 17 year old monozygotic twin with primary amenorrhea. Her twin had normal pelvic scan without evidence of mullerian anomalies. However, our case 
is of non-identical twin from Asain origin.

In September 2003, Michael P. Steinkampf, M. D., Sejal P. Dharia, M. D., and Ryan D. Dickerson (University of Alabama at Birmingham, Birmingham, Alabama), reported a case of A 20-year woman with complete vaginal agenesis (Mayer-Rokitansky-Kuster-Hauser syndrome) and right renal agenesis presented for creation of a neovagina [9]. She was one of the monozygotic twin. Her twin sister had skeletal abnormality i.e. bilateral longitudinal tibial deficiency. However, in our case the other twin is non-identical and has no abnormalities.

In 17 Aug 2015 (National Women's Hospital Auckland), Stella Ruth Milsom, [6] reported the case of 17 years female with primary amenorrhea. She was the healthy Caucasian adolescent, youngest among the twins, delivered by cesarean section due to fetal distress. There was well developed secondary characteristics, normal external genitalia, but presence of shortened and hypoplastic thumbs. Similar to our case, there was no other relevant personal history, and family history of primary amenorrhea and infertility and no any skeletal, renal, cardiac or auditory defects. There was no history of consanguinity too. Her biochemical investigations revealed normal age appropriate levels of plasma LH, FSH, estradiol, testosterone and prolactin. Trans-abdominal ultrasound demonstrated both kidneys present and normal but did not identify either a uterus or ovaries. However, pelvic MRI revealed presence of left ovary and absence of right ovary, uterus, vagina and cervix [6].

The etiology of MRKH syndrome remains unclear [14]. Several hypotheses has been postulated for the underlying mechanism including mutation of gene for anti-mullerian hormone or its receptors [15]. Majority of the case is sporadic but increased number of familial case supports genetic eitology with syndrome transmitted as autosomal dominant traits with variable expressivity. The genetics of mullerian aplasia are complex with involvement of numerous gene activity among which the HOXA genes and the WNT4 shows strong association in differentiation and regulation of various steps in development of female reproductive tract [4].

As the ovaries are functional, affected women have normal physiological hormone levels and retrival of ovum for assisted reproductive technique is possible. The main options for the diagnosis among imaging studies are ultrasound and magnetic resonance imaging (MRI). The treatment of mullerian agenesis requires multidisciplinary approach, emotional and psycosocial support, non-surgical and surgical creation of neovagina to facilitates normal sexual intercourse and requirement of in-vitro fertilization (IVF) and gestational carrier [16].

We present the 22 years female, $2^{\text {nd }}$ twin with absence of uterus, diagnosed as mullerian agenesis. The purpose of reporting this case is its atypical presentation than the other cases mentioned in the above discussion. Our case is of Asian origin, non-identical twins, presented with primary amenorrhea, absence of uterus, and bilateral functional ovaries. Unlike other cases, our case does not have any 
associated renal or skeletal abnormalities. However, hormonal assay were also within normal limits. The age of diagnosis was quite late compare to other cases mentioned.

This case is reported to create awareness to the readers that primary amenorrhea could be due to mullerian agenesis. Further research is advised to find out the association between twinning and primary amenorrhea. Early detection helps to overcome the emotional and psychological well-being, as well as fulfill sexual desires.

\section{Conclusion}

Primary amenorrhea affects approximately 5\% of amenorrheic women. It may be due to a genetic defect as mullerian agenesis. Reports of mullerian agenesis in siblings or non-identical twins are rare. We believe our case as one of the rare cases of mullerian agenesis reported in twins. This condition has psychologically devastating consequences on the affected individuals and their families. Vaginal dilators and surgical intervention allow patients to regain a degree of normality by achieving normal sexual function. Future childbearing may be possible with modern methods of assisted reproductive technology.

\section{Acknowledgements}

We would like to acknowledge all the faculty and staff from departments of Gynaecology and Obstetrics, Radiology and Pathology from 1st Clinical Medical School of Yangtze University.

\section{Conflict of Interest}

None.

\section{References}

[1] Geyoushi, B., El-Toukhy, T. and Hanna, L. (2007) Primary Amenorrhea in Non-Identical Twins: An Improbable Cause. Journal of Pediatric and Adolescent Gynecology, 20, 361-364. https://doi.org/10.1016/j.jpag.2007.04.003

[2] Duru, U.A. and Laufer, M.R. (2009) Discordance in Mayer-Von RokitanskyKüster-Hauser Syndrome Noted in Monozygotic Twins. Journal of Pediatric and Adolescent Gynecology, 22, e73-e75. https://doi.org/10.1016/j.jpag.2008.07.012

[3] Burina, A., Sinanović, O., Mujagić, S., et al. (2012) Open Access Scientific Reports.

[4] Morcel, K., Camborieux, L. and Guerrier, D. (2007) Mayer-Rokitansky-Küster-Hauser (MRKH) Syndrome. Orphanet Journal of Rare Diseases, 2, 13. https://doi.org/10.1186/1750-1172-2-13

[5] Shah, V.N., Ganatra, P.J., Parikh, R., et al. (2013) Coexistence of Gonadal Dysgenesis and Mayer-Rokitansky-Kuster-Hauser Syndrome in 46, XX Female: A Case Report and Review of Literature. Indian Journal of Endocrinology and Metabolism, 17, S274. https://doi.org/10.4103/2230-8210.119605

[6] Milsom, S.R., Ogilvie, C.M., Jefferies, C., et al. (2015) Discordant Mayer-Rokitansky-Kuster-Hauser (MRKH) Syndrome in Identical Twins-A Case Report and Implications for Reproduction in MRKH Women. Gynecological Endocrinology: 
The Official Journal of the International Society of Gynecological Endocrinology, 31, 684-687. https://doi.org/10.3109/09513590.2015.1032928

[7] Rall, K., Eisenbeis, S., Barresi, G., et al. (2015) Mayer-Rokitansky-Kuster-Hauser Syndrome Discordance in Monozygotic Twins: Matrix Metalloproteinase 14, Low-Density Lipoprotein Receptor-Related Protein 10, Extracellular Matrix, and Neoangiogenesis Genes Identified as Candidate Genes in a Tissue-Specific Mosaicism. Fertility and Sterility, 103, 494-502.e3. https://doi.org/10.1016/j.fertnstert.2014.10.053

[8] Rall, K., Barresi, G., Walter, M., et al. (2011) A Combination of Transcriptome and Methylation Analyses Reveals Embryologically-Relevant Candidate Genes in MRKH patients. Orphanet Journal of Rare Diseases, 6.

[9] Steinkampf, M.P., Dharia, S.P. and Dickerson, R.D. (2003) Monozygotic Twins Discordant for Vaginal Agenesis and Bilateral Tibial Longitudinal Deficiency. Fertility and Sterility, 80, 643-645. https://doi.org/10.1016/S0015-0282(03)00758-1

[10] Rall, K., Eisenbeis, S., Henninger, V., et al. (2015) Typical and Atypical Associated Findings in a Group of 346 Patients with Mayer-Rokitansky-Kuester-Hauser Syndrome. Journal of Pediatric and Adolescent Gynecology, 28, 362-368. https://doi.org/10.1016/j.jpag.2014.07.019

[11] Wottgen, M., Brucker, S., Renner, S.P., et al. (2008) Higher Incidence of Linked Malformations in Siblings of Mayer-Rokitansky-Kuster-Hauser-Syndrome Patients. Human Reproduction (Oxford, England), 23, 1226-1231. https://doi.org/10.1093/humrep/den059

[12] Herlin, M., Højland, A.T. and Petersen, M.B. (2014) Familial Occurrence of Mayer-Rokitansky-Küster-Hauser Syndrome: A Case Report and Review of the Literature. American Journal of Medical Genetics Part A, 164, 2276-2286. https://doi.org/10.1002/ajmg.a.36652

[13] Hall, J.G. (2003) Twinning. The Lancet, 362, 735-743. https://doi.org/10.1016/S0140-6736(03)14237-7

[14] Kobayashi, A. and Behringer, R.R. (2003) Developmental Genetics of the Female Reproductive Tract in Mammals. Nature Reviews Genetics, 4, 969. https://doi.org/10.1038/nrg1225

[15] Yakasai, I., Daneji, S., Natasha, A., et al. (2015) Late Presentation of Mayer-Rokitansky-Kuster-Hauser Syndrome in the Tropics-Northern Nigeria.

[16] Ben-Rafael, Z., Bar-Hava, I., Levy, T., et al. (1998) Simplifying Ovulation Induction for Surrogacy in Women with Mayer-Rokitansky-Kuster-Hauser Syndrome. Human Reproduction (Oxford, England), 13, 1470-1471.

https://doi.org/10.1093/humrep/13.6.1470 